\title{
UN FANTASMA RECORRE LA PSIQUIATRÍA EUROPEA: LA IGLESIA DE LA CIENCIOLOGÍA.
}

Recientemente ha tenido lugar en Valencia la exposición "Psiquiatría: destruyendo vidas y familias", que constituye un durísimo ataque contra los profesionales de Salud Mental, aunque sus destinatarios son todos los ciudadanos, hayan tenido o no relación con nuestros servicios. La muestra cuenta con la recomendación del Ministerio de Interior por su "utilidad pública", según se destaca en la publicidad, y proyecta exhibirse en diversas ciudades españolas por iniciativa de la Comisión Ciudadana de Derechos Humanos, sección española de la CCHR (www.ccdh.es), que se dedica a denunciar todo tipo de violaciones psiquiátricas a través de sus cientos de filiales desplegadas por los cinco continentes. Dicha entidad fue fundada en 1969 por la Iglesia de la Cienciología, una hermandad por completo ajena al universo científico, aunque cuenta con el respaldo de Thomas Szasz --paradójicamente profesor emérito de psiquiatría--, que destacó en las últimas décadas por sus radicales aportaciones de contenido antipsiquiátrico.

La exposición está articulada en torno a un impactante audiovisual, "La psiquiatría, una industria de la muerte", profusamente documentado y editado con todo lujo de efectos especiales en 14 capítulos sucesivamente proyectados en diferentes escenarios. En cada uno de ellos se muestran paneles donde se resaltan los abusos y atropellos atribuidos a los profesionales de Salud Mental, hasta componer un amplio catálogo de perversiones donde se recogen todo tipo de desmanes. Así se hace notar al comienzo en su declaración de intenciones, cuando se invita a los asistentes a unirse a su cruzada contra los "incontrolados" psiquiatras en la "revelación pública de sus prácticas criminales", ofreciendo todo su arsenal de datos "contra este flagelo". Doscientos años de historia de nuestra disciplina son recorridos a través de una siniestra "senda de la destrucción", que comienza con la relación minuciosa de los métodos de contención, los salvajes tratamientos precientíficos y los estragos de la violencia dentro de los manicomios. Los padres de la psicología, Wundt y Pavlov, son criticados por sus experimentos degradantes del ser humano a la categoría de animales, junto a las aportaciones de sus colegas Galton y Spencer. Todos ellos son acusados de preconizar un rudimentario darwinismo social, que desembocaría en su grado más abyecto durante el delirio eugenésico de la barbarie nazi. Psiquiatras y psicólogos, según se sostiene con rotundidad, serían los responsables últimos del holocausto sufrido por millones de personas por servir de respaldo científico del genocidio; un crimen semejante al cometido por la psiquiatría soviética bajo la dictadura estalinista, al contribuir a una represión más cualificada durante las purgas y torturas de los disidentes. Aún después, según los promotores, el racismo del apartheid sudafricano y hasta el fanatismo militante del $K u$ Klux Klan encontrarían adecuado respaldo ideológico entre nuestras disciplinas, de manera semejante a la represión de minorías en China 
o las operaciones de limpieza étnica en la guerra de los Balcanes. Incluso se destaca la condición de psiquiatra del lugarteniente de Bin Laden para evidenciar la peligrosidad manifiesta del terrorismo psiquiátrico.

Los expertos de la mente, sin excepción de escuelas teóricas u orientaciones ideológicas, estaríamos detrás de los episodios más siniestros de la historia, poniendo nuestros privilegiados conocimientos de manipulación y dominio de las personas al servicio de las causas más protervas. Fuera a través de las insoportables torturas que hacían posible las terapias de choque sucesivamente innovadas por Meduna, Sakel o Cerletti, o bien por medio de la psicocirugía de Egas Moniz, enseguida optimizada por Freeman. Y ya en nuestros días, la ciencia psiquiátrica no habría cesado en su carrera de maldad institucionalizada gracias a los poderosos psicofármacos, que permiten tener bajo control a tantos millones de pacientes, siguiendo el ejemplo de los gurús de la experiencia psicodélica. Aunque numerosos iconos del pop y estrellas cinematográficas no hayan podido escapar a su impacto destructivo, dejando un reguero de cadáveres exquisitos desde Marilyn Monroe y Elvis Presley hasta Charly Parker o Michael Jackson.

Previamente habrá sido preciso diseñar un catálogo de síntomas que permitiera patentar el remedio para la invención de nuevas enfermedades en la siniestra década del cerebro. La propagación abusiva de TDAH entre los colegios e institutos sería el ejemplo más claro de esta tendencia consumista, que encuentra en la medicalización de los menores un inmenso mercado para cubrir las ambiciones de la industria farmacéutica y los codiciosos psiquiatras que coinciden en la empresa común de seguir el rastro seguro del dinero. "Una pseudociencia", en definitiva, que sostiene sus prácticas fraudulentas y ajenas a la ética profesional con objetivos meramente monetarios; cuando no ciertamente mezquinos, como demuestra el elevado número de involucrados en delitos sexuales de toda índole o la variedad de conductas criminales protagonizadas por muchos expertos. No es de extrañar el éxito de taquillas garantizado por la figura del psiquiatra/psicópata, un estereotipo bien arraigado en el universo cinematográfico que gracias a la amplia difusión televisiva sirve para desenmascarar la condición malsana de tantos farsantes como se reclutan es este gremio. Menos mal que algunos de los más carismáticos rostros de Hollywood y vips comprometidos vienen prestando su respaldo a la causa cienciológica para que salga a la luz tanto dislate y la verdadera ciencia pueda seguir su rentable apostolado eclesiástico.

Así hasta llegar a constituir el imperio multinacional que hoy compone la Iglesia de la Cienciología, poderosa secta con una facilidad de penetración por todo el mundo tan acreditada como su reincidencia en las denuncias judiciales que recibe allí donde inician su cometido. No es nuestro cometido abordar aquí la estructura y el entramado logístico de organizaciones (Narconon, Dianética, CCHR...) de esta cofradía religiosa, a buen seguro infranqueable para muchos Gobiernos --sin ir más lejos el nuestro--, que ha logrado ser recibida en las Cortes por destacados parlamen- 
tarios españoles. Pero si calificaremos de perniciosa la influencia que pueda ejercer sobre sus adeptos a través de los cursos de "tecnología espiritual" que promueven, a costa de amplísimos colectivos como el de los familiares y usuarios de los servicios psiquiátricos, que la OMS cuantifica en más de 350 millones de pacientes por todo el mundo. Por eso resulta indignante que el Ministerio del Interior se haya prestado a avalar esta exhibición calumniosa y denigrante para los profesionales de Salud Mental, cuya resonancia pública sólo puede causar confusión y engaño, mereciendo nuestra más enérgica protesta y petición de responsabilidades.

La Asociación Española de Neuropsiquiatría, que desde su fundación ha venido mostrando su compromiso inequívoco en la lucha por los derechos de los enfermos mentales y en la renovación del marco jurídico y administrativo de su asistencia, no debería tolerar estos atropellos infamantes. Urge poner fin a esta campaña de desprestigio, denunciando a los promotores de esta fantasmagórica comisión que se ocultan tras la perversión de las palabras con las que los sectarios esconden sus verdaderas intenciones.

Cándido Polo Griñán 